\title{
The prevalence of malposition third molar with traumatic ulcer
}

\author{
Tun Shafiqah Tun Abdul Majid*, Ida Ayu Astuti*, Tenny Setiani Dewi** \\ *Department of Oral and Maxillofacial Surgery Faculty Of Dentistry Universitas Padjadjaran \\ **Department of Oral Medicine Faculty of Dentistry Universitas Padjadjaran
}

\begin{abstract}
Introduction: Malposition third molar is a condition when the third molar is erupted but in an abnormal position and relation to maxilla and mandible. Due to a frequent mechanical abrasion between the third molar and oral mucosa, a traumatic ulcer resulted. Hence, this research aims to determine the prevalence of traumatic ulcer in regards to a malposed third molar in Oral and Maxillofacial Surgery Department, Rumah Sakit Hasan Sadikin in a periodic of August 2008 to August 2011. Methods: The samples taken were all medical records which stated the coveted diagnosis which satisfied the variables of the age, gender and malposed third molar. The method of this research was descriptive retrospective study by using secondary data. Results: This research ratiocinates that the prevalence of malposition third molar with traumatic ulcers is $0.012 \%$ with tooth 18 caused most traumatic ulcer. Females predominant this condition and it is common in the third decade of age. Conclusion: Derived from the outcomes of this research, it can be concluded that the prevalence of malposition third molar with traumatic ulcer in Oral and Maxillofacial Surgery Department of Rumah Sakit Hasan Sadikin from August 2008 to August 2011 is $0.012 \%$.
\end{abstract}

Keywords: Malposition, Third molar,Traumatic ulcer

\section{INTRODUCTION}

Wisdom teeth, also known as the third molars, are the last four teeth to erupt in the mouth. This generally occurs between the ages of 17 to 21,1 at a time of life that has been called the 'Age of Wisdom'. Hence, the third molars are always called as the wisdom teeth.

But somehow, not all third molars will erupt normally in the right angles and positions. Some are fully erupted, but angulated while some are not fully erupted or in other word, impacted. The impacted third molar is defined as a tooth that cannot, or will not erupt into its normal functioning positions and is therefore, pathologic and requires appropriate1. While malposed third molar is also a type of impacted third molar, defines a third molar which is erupted either partially or fully, but in an abnormal position. ${ }^{2}$

This condition will not only bring pain to one, but it can also associates with some other complications involving the oral mucosa and patient's general health like dental crowding, pericoronitis and traumatic ulcer. $^{3}$ This study describes a bead on traumatic ulcer which occurs due to a malposed third molar as it is one of the most common complications involving the malpositioned third molar to the oral mucosa. 
Traumatic ulcer in this case is mainly caused by the excessive mechanical forces due to the abnormal positions and alignment of the malpositioned third molar in the oral mucosa at the buccal area, especially. With the constant and persistent intensity towards the soft tissue of the oral mucosa, traumatic injury will happen and this will cause pain as well as discomfort to the patient. ${ }^{4}$ Broadly speaking, this case is a usual finding in the world of dentistry especially in young adults. However, people tend to neglect and mostly only go to the dentists when the condition is severe as it is secondarily infected and progressed towards abscess, cyst or tumor. ${ }^{5}$

Thisinfluenced thewriter to discuss further on this issue as there was no previous study performed on this matter which stated its preponderance. This paper includes the treatments and preventions, with the main purpose to find its prevalence in the Department of Oral and Maxillofacial Surgery, Rumah Sakit Hasan Sadikin, Bandung (RSHS).

Rumah Sakit Hasan Sadikin has been found as the best location for the research by the writer due to the well-known fact that this hospital is the central reference of the whole West Java and has been certified by ISO (International organization for standardization) in 2010, also RSHS is The Medical School and Teaching Hospital.

\section{METHODS}

This study was conducted in descriptive survey by collecting secondary data of the mentioned case from the medical records of Oral and Maxillofacial Surgery Department, Rumah Sakit Hasan Sadikin (RSHS). The population in this research was all medical records in Oral and Maxillofacial Surgery Department (RSHS) within the period of August 2008 to August 2011. Whilst the samples were total sampling, where the whole population taken as samples. Since this research was made based on the data collected of medical records, the materials needed are Department of Oral and Maxillofacial Surgery Patients' Logbook, Medical records anf stationaries. The data were obtained from the log book and medical records which were grounded by the diagnosis of traumatic ulcer et cause impacted third molar(s), taken from a August 2008 to August 2011. The other data obtained were gender and age of the patients. The data were then summarized in the forms of figures and percentages.

\section{RESULTS}

The collected data obtained from the research are presented in bar and pie charts in order to identify the prevalence of malposition third molar with traumatic ulcer. The data from the medical records of Oral and Maxillofacial Surgery Department (OS) of RSHS are summarized and categorized according to the desired variables which are age, gender and malposition third molar. Based on the patients log book, reapproximately 12,735 of OS patients registered and treated from August 2008 to August 2011. Figure 1 ex-
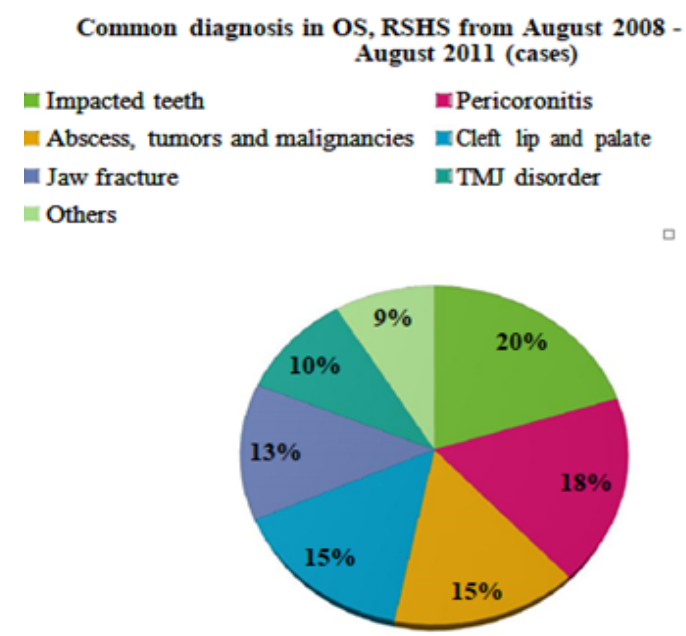

Figure 1. Common Diagnosis in department of Oral maxillofacial surgery, RSHS from August 2008 -August 2011

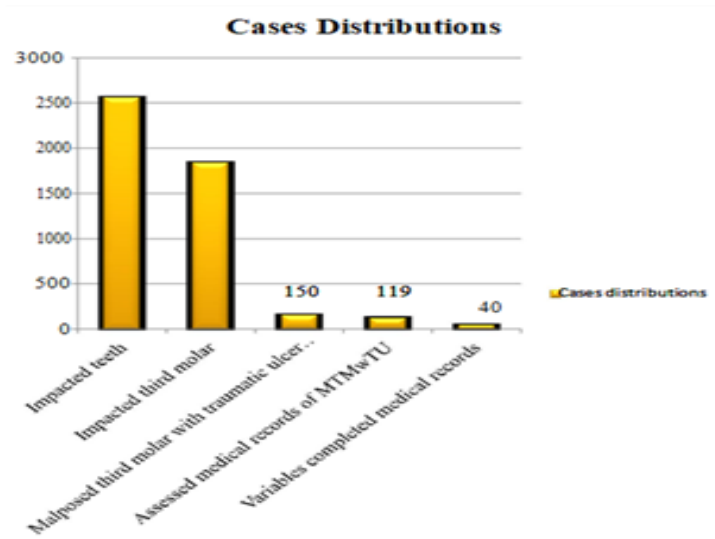

Figure 2. Cases Distributions from August 2008 -August 2011

plain on the common diagnosis of the patients. By means of the research purposes and variables involved, there were 150 medical records stated the diagnosis wanted. However, 
due to certain circumstances, only 119 medical records could be accessed and 40 medical records exclusively fulfilled all the variables. Based on the diagram, it is known that Impacted Teeth is the most common diagnosis with the value of 2557 cases, followed by Pericoronitis at 2301 cases, Abscess, Cyst, Tumor and other Malignancies at 1917 cases, Cleft Lip and Palate at 1917 cases, Jaw Fractures at 1662 cases, Temporomandibular Joint Disorder at 1278 cases and last but not least, other miscellaneous diagnosis such as periodontitis and gingivitis at 1103 cases.

These cases are summarized in percentage as stated in the Figure above. From two thousand five hundred and fifty-seven (2557) cases of impacted teeth, indicating $20 \%$ of the population, it was narrowed down to impacted third molar cases, which was 1836 . Subsequently, the numbers were specified in search of the diagnosis of Malposition third molar with Traumatic Ulcer (MTMWTU) and there were 150 cases found (figure 2).

Unfortunately, from these 150 cases searched through the Medical Records Department, only 119 medical records were found and accessible. Of 119 medical records, only 40 medical records were written completely with the right diagnosis and variables desired which are age, gender and the malposition third molar. The age of all 40 patients are summarized in Table 1, the most common age group involved was the third decade, which are patients in the age of 21 to 30 years old.

They exhibit the largest number with 19 cases which is $47.5 \%$, followed by patients in fourth decade at 11 cases, patients in second decade which are around 16 to 20 years old at 4 cases, and patients at sixth, fifth and seventh decades at 3,2 and 1 cases individually. It is known that from 40 patients, females dominated with 28 patients while males were 12 patients.

Table 1. Malposition Third Molar with Traumatic Ulcer According to Age Group

\begin{tabular}{ccc}
\hline Age group & Frequency & Percentage (\%) \\
\hline $16-20$ & 4 & 10 \\
$21-30$ & 19 & 47.5 \\
$31-40$ & 11 & 27.5 \\
$41-50$ & 2 & 5 \\
$51-60$ & 3 & 7.5 \\
$61-70$ & 1 & 2.5 \\
\hline
\end{tabular}

Based on the medical records, there were several patients which complained of more than one malposed third molar which caused the traumatic ulcer at site; and most involved the opposite jaw at the same side. Hence, there were 14 complains on tooth 18 which is upper right third molar, 12 complains on tooth 28 which is upper left third molar, 9 complains on tooth 38 which is lower left third molar whilst 10 complains on tooth 48 which is lower right third molar. Maxillary right and left third molars signify higher amount compared to mandibularry right and left third molars.

\section{DISCUSSION}

This research was conducted at the Department of Oral and Maxillofacial Surgery, Rumah Sakit Hasan Sadikin Bandung from November 2011 to April 2012, with the data taken retrospectively from August year 2008 to August year 2011 using Medical Records. The guideline of choosing the completed medical records was the diagnosis 'traumatic ulcer et causa malpostion/impaction' at the log book, which means patient having a traumatic ulcer at site of the malposed or impacted third molar.

The criteria observed and complaints with the variables desired by this research such as age, gender and the malposed third molar. From the log book of three consecutive years, the researcher had found 150 cases of malposed third molar with traumatic ulcer of 12,735 miscellaneous cases. This gives the result of $0.012 \%$ in prevalence.

However, as stated earlier, there were only 119 medical records found in the Medical Records Department and pitiably, most of these records were not completely written. As much as 40 medical records taken as the sample as these exclusively fulfilled the diagnosis and variables needed.

These 40 records out of 150 needed, gives the preponderance of only $26.7 \%$ completely written medical records. Hence, the discussion is based on the data commenced by these 40 medical records. Based on the anamnesis of all 40 medical records, it is found that patients came displeasured with pain at the site of having malposed third molar.

Chief complains stated that patients constantly biting the cheek due to the angled tooth and caused discomfort. Some patients reported that they were aware of the condition but only 
came for treatment when the pain was unbearable. After a thorough extraoral and intraoral examination, there was an ulcer found nearby the malposed third molar which were characterized as a yellowish-white depression surrounded by erythematous irregular border with the diameter of less than one centimeter. All patients were healthy systemically with no abnormalities in vital signs.

Subjects were diagnosed with traumatic ulcer et causa malposition third molar due to the site of injury as traumatic ulcers are the consequence of mechanical injury resulting from inadvertent biting of the mucosa. ${ }^{6}$ And the known cause of injury based on anamnesis and examinations was the malposed third molar which constantly caused friction with the oral mucosa resulting a trauma.

Patients were inquired to take a panoramic x-ray as a diagnostic purpose and then proceeded with removal of the third molar by means of odontectomy. Patients were then given analgesics and antibiotics as post-operative management. No other medications were given for the traumatic ulcer as the source of irritation is eliminated, the traumatic ulcer will heal by itself in approximately ten to fourteen days. ${ }^{6}$

Upon one week control, patients had null complaints on pain and discomfort. To discuss this matter as a whole, in a previous study done by Alamsyah and Situmorang in 2005, they stated that out of 7468 patients, there were $28.3 \%$ had impacted third molar.

Hence, grounded by the results gotten from months of studies, it is testified that impacted third molar is not something unusual especially in young adults since the third molar shall erupt at the age of 18-24 years old. ${ }^{7}$

This is proven in Table 1 with the third decade ranging from 21 years old to 30 years old at $47.5 \%$, since it is the period of time when the third molar are erupting or erupted, be it in favourable or unfavourable position. By age 24 years old, $95 \%$ of all third molars that will erupt have completed their eruption. ${ }^{7}$

The rise of the number, other than because it is due to the periode life phase of population at the age of twenties which require work or studies. A malposition third molar with traumatic ulcer must have been disturbing the quality of their daily lives, these population seek treatments earlier. 8 However, it is highly convinced that the number should be higher but most probably due to negligence, the affected roles preferred to leave it untreated. The same presumption implies to patients in the fourth decade, as the second highest. Different growth rates had given $10 \%$ of patients at the age of 16 to 20 years old whom have had an erupted malposed third molar with traumatic ulcer at site. While patients in their sixth, fifth and seventh decades showed consecutively lower number compared to those mentioned earlier. The declination in numbers with increasing in age might be due to previous operative removal to most, or simply due to negligence. ${ }^{9,10}$

Then the subjects are categorized based on gender presented females have higher percentage than males, at $70 \%$ compared to $30 \%$ agreeing to a previous study done by Ahmad Khan et. al where they have found that females have higher tendency of having impacted or malpositon third molar with the percentage of $54 \%$ compared to males at $46 \%$.

Anatomically speaking, the bones in a female body complete their development sooner than those in the male body. Female bones complete their development around age 18 years old, whi around age 22 years old. This is part of the explanation behind the difference in the average size of male and female bones as the male bones continue to grow and develop longer, they also become larger on average and have more pronounced corners. ${ }^{11}$

Thus, the relative size of several key features can be used to identify a male versus female skeleton. One of the obvious distinction is in males, the jaw bone is generally larger and more pronounced whilst the females have narrower and smaller jaw. ${ }^{12}$

With a reflectively narrower and smaller jaw compared to males, females have littler space for all teeth to eru more the third molar which requires enough space posteriorly. With excessive frictions from the malposed third molar to the oral mucosa in a constricted space over time, traumatic ulcer is more likely to occur too. ${ }^{13}$

Thus, this scenario is predominantly in females rather than males. Tooth 18 proposed the highest number of complains which caused pain, discomfort and traumatic ulcer. Followed by tooth 28, 48 and 38 . Based on the chief complaints in the medical records, most patients quetched about cheek biting since the malposed tooth which all were recorded 
as buccoversion, and its opposition clashed with each other, in example, tooth 18 and 48 collided and caused mild cheek biting which eventually caused a severe traumatic ulcer after some time. While some complain on either upper or lower erupted malpositionly, also recorded buccoversion third molar which constantly brushing against the cheek mucosa without cheek biting with the opposition tooth. From the anamnesis and chief complains of the samples observed, it was found that buccoversion malposed teeth contributes to a traumatic ulcer at the buccal mucosa with maxillary teeth having the most number. However, on referral to observations, text books and journals read, it is highly convinced that other type of malposed third molar may cause this condition, as well as the traumatic ulcer may occur at other location too. The diagnosis looked for, which is traumatic ulcer et causa malposition third molar was found only 150 in three years where as the probability distribution might be higher. This had made only 40 medical records taken as samples of this study. Even though all 40 are not completely written with classification and such, but the samples had complete diagnosis and all the variables wanted which keywords were "age, gender and malposed third molar".

As brought up earlier, the prevalence of malposed third molar with traumatic ulcer may be higher than just $0.012 \%$ and may involved other types of malposition third molar as well as the location of traumatic ulcer as $0.012 \%$ were absolute buccoversion malposed third molar with buccal mucosa as the location.

\section{CONCLUSION}

Derived from the outcomes of this research, it can be concluded that the prevalence of malposition third molar with traumatic ulcer in Oral and Maxillofacial Surgery Department of Rumah Sakit Hasan Sadikin from August 2008 to August 2011 is 0.012\%.

\section{REFERENCES}

1. Chestnutt IG, Gibson J. Clinical Dentistry $3^{\text {rd }}$ Ed. United Kingdom: Churchill Liverstone Elsevier. 2007

2. Thoma $\mathrm{KH}$. The Management of The Malposed Third Molar. J Dental Research. 2006;12(1):175-208

3. Laskin DM. Some Wisdom About the Removal of Wisdom Teeth. J Practical Hygiene 2001;10(2):15-20.

4. Compilato DN, Cirillo N. Termine AR, Kerr C, Paderni, D. Ciavarella G. Campisi. Long-standing oral ulcers : proposal for a new "S-C-D classification system ." J Oral Pathol Med. 2009;38(5):241-253.

5. Haug RH, Perrott DH, Gonzalez ML, Talwar RM. The American Association of Oral and Maxillofacial Surgeons Age-Related Third Molar Study. J Oral Maxillofac Surg. 2005 Aug;63(8):1106-14.

6. Sonis ST, Fazio RC. Principles and Practice of Oral Medicine $2^{\text {nd }}$ Ed. Massachusetts, Boston: W.B. Saunders Company. 2003. 345-351 pp.

7. Ness GM, Peterson LJ. Impacted Teeth. In Principles of Oral and Maxillofacial Surgery. Ontario:BC Decker Inc. 2004. 139-153 pp.

8. Rolph J. The Wisdom of Removing the Wisdom Tooth. 2006.

9. Khan AU, Khitab MT. Khan. Impacted Mandibular Third Molars : Pattern of Presentation and Postoperative Complications. J Pakistan Oral \& Dental. 2010;30(2):307-311.

10. The Centre for Review on Dissemination, York. Effectiveness Matters Prophylactic Removal of Impacted Third Molars : Is It Justified . J Ort. 1999;26(2)(June):149-151.

11. Widamayanti Y. Kumpulan Catatan IImu Kedokteran Kehakiman $4^{\text {th }}$ Ed. Jakarta: MediaDIKA. 2002

12. Main C. The Difference Between Male and Female Skeletons. TenReviews. 2012.

13. Houston G, Ozcelik O, Haytac MC, Akkaya M. latrogenic trauma to oral tissues. J Periodontal. 2005;76(10):1793-7. 